\title{
Circadian Rhythm of Patients with Disorders of Consciousness
}

\author{
Jing Wang ${ }^{1}$, Haibo $\mathrm{Di}^{1}$, Nantu $\mathrm{Hu}^{1,3}$, and Steven Laureys ${ }^{2}$ \\ ${ }^{1}$ Department of Neurology, Hangzhou Normal University, China \\ ${ }^{2}$ Department of Neurology, Coma Science Group, University, Belgium \\ ${ }^{3}$ Department of Psychology and Cognitive Science, East China Normal University, China
}

Submission: November 01, 2018; Published: November 28, 2018

*Corresponding author: Haibo Di, International Vegetative State and Consciousness Science Institute, Hangzhou Normal University, Hangzhou, China.

\begin{abstract}
Patients with Disorders of Consciousness (DOC) exhibit arousal fluctuations, showing periods of circadian sleep-wake. Circadian rhythms are the outward manifestation of an endogenous timing system. The diagnosis of patients does not only rely on behavioral responsiveness during process, but also based on the rhythm of patients. Therefore, it is important to know the circadian rhythm of DOC patients. We also need to be aware of the importance of adjusting circadian rhythm for DOC patient in diagnosis and treatment.
\end{abstract}

Keywords: Disorders of consciousness, Circadian rhythm, Assessment, Arousal

\section{Opinion}

In recent years, the diagnosis and treatment of Disorders of Consciousness (DOC) have gained attention. DOC include the unresponsive wakefulness syndrome (UWS, formerly known as vegetative state) [1,2] and Minimally Conscious State (MCS) [3]. Both UWS and MCS patients exhibit arousal fluctuations, showing periods of eye-opening and eye-closing, which resemble circadian sleep-wake cycles (also known as circadian rhythms) [4]. However, the arousal fluctuations effect the diagnosis of behavioral assessment during Coma Recovery Scale-Revised (CRS-R, 'gold standard' for diagnosing DOC) process in clinic [5]. Therefore, we need to know that if all DOC present exhibit circadian rhythm and whether the evaluation of rhythm is crucial for all DOC patient before the CRS-R assessment.

Circadian rhythms are the outward manifestation of an endogenous timing system [6]. They are generated by the central endogenous clock that resides in the Supra Chiasmatic Nucleus (SCN) of the anterior hypothalamus $[7,8]$. The SCN synchronizes all the other intrinsic clocks and integrates information from the environment to form coherent rhythms that are near 24 -h periods $[9,10]$. When periodic synchronizing cues from the environment are absent, the endogenous circadian rhythm (i.e., free-running rhythm) appears. This free-running rhythm deviates from its normal cycle and it is usually longer than $24 \mathrm{~h}$, around 24.18 $\mathrm{h}$ [11-13]. In fact, circadian rhythms of electrophysiology, skin temperature, hormone secretion, as well as blood pressure and heart rate $[14,15]$ have been observed in some patients with UWS and MCS. However, when exposing to monochromatic light during night, MCS patients and healthy person displayed lightinduced suppression of melatonin but patients in UWS didn't displayed it [16]. Since the hormone melatonin is considered to be the best circadian phase index, this finding indicates that environmental lighting may not influence the circadian rhythms in UWS patients.

A previous study examining circadian rhythm variables of 3 UWS patients', including systolic blood pressure, diastolic blood pressure and heart rate. The authors report circadian periods of $24.25 \mathrm{~h}, 24.18 \mathrm{~h}$, and $24.14 \mathrm{~h}$ [15]. In studies on healthy participants where environmental cues were controlled, the circadian period changes to something close to the free-running period [11,17-19]. Then, can we say that UWS patients present free-running periods due to the lack of conscious awareness of the environment and MCS patients can be synchronized with the outside world and consequently form 24-h cycles? Several previous studies on other circadian rhythms seem in line with our opinion. Among all the external time cues, light is the most powerful one [20,21]. Normally, exposure to light at night suppresses melatonin secretion Guaraldi P et al [16]. investigated the light-induced melatonin suppression in a group of 6 UWS patients and 9 healthy volunteers, and found that in contrast to the controls, UWS patients displayed no significant changes of melatonin during light-exposure at night. Another study by De Weer AS et al [22]. evaluated environmental influences on circadian variations in motor patterns in 3 MCS and 1 comatose patient. They observed that motor activity was correlated with presence and actions of other persons in 2 traumatic MCS 


\section{Open Access Journal of Neurology \& Neurosurgery}

patients. Furthermore, a recent study showed that arousal subscale scores of CRS-R were closely related to the circadian core body temperature variation, which provided evidence for their association between circadian body temperature rhythms and consciousness levels in DOC patients [23].

In conclusion, it suggests that a relationship between circadian rhythm and consciousness might exist. We all know that the CRS-R diagnosis of patients does not only rely on behavioral responsiveness during process, but also based on the rhythm of patients. It could therefore be a useful complement to behavioral diagnosis and decrease the rate of misdiagnosis. Moreover, it's necessary to assess the period of arousal before using CRS-R to assess the consciousness of DOC patients and the best time of the CRS-R evaluation can be chosen according the patients' own rhythm due to the fluctuation of arousal.

\section{Conflict of Interest}

The authors declare that they have no any economic interest and any conflict of interest exists.

\section{References}

1. Laureys S, Celesia GG, Cohadon F, Lavrijsen J, León-Carrión J, et al. (2010) Unresponsive wakefulness syndrome: a new name for the vegetative state or apallic syndrome. BMC medicine 8: 68.

2. Monti MM, Laureys S, Owen AM (2010) The vegetative state. Bmj 341: c3765.

3. Giacino JT, Ashwal S, Childs N, Cranford R, Jennett B, et al. (2002) The minimally conscious state: definition and diagnostic criteria. Neurology 58(3): 349-353.

4. Wislowska M, Del Giudice R, Lechinger J, Wielek T, Heib DPJ, et al. (2017) Night and day variations of sleep in patients with disorders of consciousness. Sci rep 7(1): 266.

5. Cortese MD, Riganello F, Arcuri F, Pugliese ME, Lucca LF, et al. (2015) Coma recovery scale-r: variability in the disorder of consciousness. BMC Neurol 15: 186.

6. Evans JA, Gorman MR (2016) In synch but not in step: circadian clock circuits regulating plasticity in daily rhythms. Neuroscience 320: 259280.

7. Meijer JH, Michel S, Vanderleest HT, Rohling JH (2010) Daily and seasonal adaptation of the circadian clock requires plasticity of the SCN neuronal network. Eur j neurosci 32(12):2143-51.

8. Golombek DA, Rosenstein RE (2010) Physiology of circadian

This work is licensed under Creative

Commons Attribution 4.0 Licens

DOI: 10.19080/OAJNN.2018.09.555763 entrainment. Physiol Rev 90(3): 1063-1072.

9. Reppert SM, Weaver DR (2002) Coordination of circadian timing in mammals. Nature 418: 935-941.

10. Matsumoto M, Sugama J, Okuwa M, Dai M, Matsuo J, et al. (2013) Noninvasive monitoring of core body temperature rhythms over $72 \mathrm{~h}$ in 10 bedridden elderly patients with disorders of consciousness in a Japanese hospital: a pilot study. Arch gerontol geriatr 57(3): 428-432.

11. Czeisler CA, Duffy JF, Shanahan TL, Brown EN, Mitchell JF, et al. (1999) Stability, precision, and near-24-hour period of the human circadian pacemaker. Science 284(5423) : 2177-2181.

12. Cologan V, Drouot X, Parapatics S, Delorme A, Gruber G, et al. (2013) Sleep in the unresponsive wakefulness syndrome and minimally conscious state. J neurotrauma 30(5): 339-346.

13. Fukudome Y, Abe I, Saku Y, Matsumura K, Sadoshima S, et al. (1996) Circadian blood pressure in patients in a persistent vegetative state. Am j physiol 270(5pt 2): R1109-1114.

14. Bekinschtein TA, Golombek DA, Simonetta SH, Coleman MR, Manes FF (2009) Circadian rhythms in the vegetative state. Brain injury 23(11): 915-919.

15. Guan J, You C, Liu Y, Liu Y, Zhang R, et al. (2011) Characteristics of infradian and circadian rhythms in the persistent vegetative state. J Int Med Res 39(6): 2281-2287.

16. Guaraldi P, Sancisi E, La Morgia C, Calandra-Buonaura G, Carelli V, et al. (2014) Nocturnal melatonin regulation in post-traumatic vegetative state: a possible role for melatonin supplementation? Chronobiol internat 31(5): 741-745.

17. Eastman CI, Molina TA, Dziepak ME, Smith MR (2012) Blacks (African Americans) have shorter free-running circadian periods than whites (Caucasian Americans). Chronobiol Int 29(8): 1072-1077.

18. Arendt J (2010) Shift work: coping with the biological clock. Occup Med (Lond)60(1): 10-20.

19. Scheer FA, Wright KP Jr, Kronauer RE, Czeisler CA (2007) Plasticity of the intrinsic period of the human circadian timing system. PloS one 2(8): e721.

20. Lack LC, Wright HR (2018) Chronobiology of sleep in humans. Cellular mol life sci 64(10): 1205-1215.

21. Brzezinski A (1997) Melatonin in humans. N Engl J Med 336(3): 186195.

22. De Weer AS, Da Ros M, Berré J, Mélot C, Goldman S, et al. (2011) Environmental influences on activity patterns in altered states of consciousness. Eur J Neurol 18(12): 1432-1434.

23. Blume C, Lechinger J, Santhi N, del Giudice R, Gnjezda MT, et al. (2017) Significance of circadian rhythms in severely brain-injured patients: a clue to consciousness? Neurology 88(20): 1933-1941.

Your next submission with Juniper Publishers will reach you the below assets

- Quality Editorial service

- Swift Peer Review

- Reprints availability

- E-prints Service

- Manuscript Podcast for convenient understanding

- Global attainment for your research

- Manuscript accessibility in different formats

( Pdf, E-pub, Full Text, Audio)

- Unceasing customer service

Track the below URL for one-step submission

https://juniperpublishers.com/online-submission.php 